\title{
ESTUDANTES NEGRAS UNIVERSITÁRIAS E A HERANÇA CULTURAL ESCOLAR
}

\author{
Schirlei Russi Von Dentz* \\ Ione Ribeiro Valle**
}

\begin{abstract}
Resumo
Este trabalho aborda três experiências vividas por estudantes negras cotistas da Universidade Federal de Santa Catarina (UFSC), as quais foram relatadas por meio de entrevistas. O referencial teórico aporta-se nos conceitos desenvolvidos pelo sociólogo Pierre Bourdieu, principalmente quanto aos diferentes tipos de capitais abordados pelo autor - econômico, cultural, social, simbólico, linguístico, escolar, etc. -, para a análise das trajetórias de vida escolar e universitária das entrevistadas. Destaca-se, das trajetórias de vida das estudantes, especialmente, suas heranças cultural, escolar e familiar e como elas mobilizaram essas heranças em seu favor. No campo universitário, todavia, o racismo, a discriminação de gênero e as "diferenças" se interseccionam (Kimberlé Crenshaw) para a reprodução social (Pierre Bourdieu). A isso, opõem-se as ações afirmativas, que vêm tentando romper com a lógica da reprodução social, criando as condições para novas relações no campo universitário e enriquecendo as práticas sociais nesses ambientes pela inclusão das diferenças sociais, culturais e étnicas.
\end{abstract}

Palavras-chave: Mulheres negras. Capitais. Herança cultural e escolar.

\footnotetext{
* Mestre em Educação pela Universidade Federal de Santa Catarina (UFSC). Doutoranda da mesma instituição. E-mail: schirleirussi@gmail.com

** Realizou pós-doutorado pela École des Hautes Études en Sciences Sociales - Paris e doutorado em Ciências da Educação pela Université René Descartes - Paris - V Sorbonne. É professora do Programa de Pós-Graduação em Educação (PPGE) da Universidade Federal de Santa Catarina (UFSC).E-mail: ione.valle@ufsc.br.
} 


\section{Introdução}

1 Maiores informações sobre esse departamento podem ser acessadas em: $<$ http://acoesafirmativas.ufsc.br/>.

$2 \mathrm{O}$ projeto está registrado no Comitê de Ética sob o número 48326415.0.0000.0115.
A implementação de açóes afirmativas na Universidade Federal de Santa Catarina (UFSC) permitiu, a partir de 2008, o ingresso de estudantes que tiveram a opção de concorrer, por exemplo, na modalidade de cotas étnico-raciais. Esse fato justificou a realização de diversos estudos sobre os processos dessas políticas e sobre a maneira como elas impactaram a universidade e a vida dos estudantes. Nesse contexto, nosso estudo teve o interesse em ouvir mulheres que adentraram a universidade pelas cotas étnico-raciais. $\mathrm{Na}$ oportunidade, realizamos doze entrevistas, que aconteceram da seguinte maneira: inicialmente, solicitamos ao Departamento de Política de Açóes Afirmativas ${ }^{1}$ da UFSC as informações necessárias para um primeiro contato com as estudantes, concedidas após a apresentação do parecer do Comitê de Ética em Pesquisa com Seres Humanos (CEPSH). ${ }^{2}$ Assim, conseguimos obter dados precisos sobre o quantitativo de mulheres negras cotistas devidamente matriculadas e também dados referentes aos seus nomes, endereços de e-mail, números de telefones e quais cursos elas realizavam na UFSC, campus Trindade. Depois disso, realizamos os contatos necessários para a obtenção das entrevistas, as quais foram realizadas entre março de 2015 e abril de 2016. Priorizamos localizar estudantes que tivessem ingressado na universidade entre 2010 e 2014, porque nos interessava também saber quais suas expectativas quanto ao mercado de trabalho - questão que, acreditamos, esteja mais presente na realidade das estudantes que cursam as fases finais da graduação.

Para o presente artigo, selecionamos, dessa pesquisa realizada, uma abordagem que considera apenas três dessas entrevistas, ou seja, três trajetórias de vida de estudantes negras cotistas da UFSC: uma do curso de Biologia, do Centro de Ciências Biológicas; outra do curso de Design Gráfico, do Centro de Comunicação e Expressão; e, uma do curso de Psicologia, do Centro de Filosofia e Ciências Humanas. As trajetórias selecionadas serão aqui analisadas sociologicamente, considerando-se o aporte teórico em Pierre Bourdieu (2007 
2014, 2011) e Bourdieu e Passeron (2008). Buscamos saber, principalmente, como elas se mobilizaram para o enfrentamento do processo seletivo (vestibular) e como elas narram suas experiências no Ensino Superior; a partir disso, recorremos ao conceito de "capital" para identificar quais tipos de capitais as entrevistadas mobilizaram em suas trajetórias. Além disso, para uma análise das questóes que envolvem o racismo e a discriminação, pautamo-nos na categoria "interseccionalidade", conforme esta é apresentada por Kimberlé Crenshaw (2002), que, em linhas gerais, busca a compreensão de como duas ou mais formas de subordinação se agregam. Não se trata, portanto, de uma "superposição", mas de uma "interação" que se retrata pela interseccionalidade das opressóes.

\section{Mobilizando os diferentes tipos de "capitais"}

O conceito de capital cultural foi elaborado por Pierre Bourdieu para estudar as diferentes desigualdades entre os alunos no que se refere à aprendizagem. Ele observou que as diferenças das classes sociais se faziam refletir no conhecimento por consequência de os alunos terem ou não acesso às diversas formas de cultura presente nas famílias. Isso implicou romper com as ideias que consideram tanto o sucesso quanto o fracasso escolar como efeito direto das "aptidões" naturais, além de permitir romper com as teorias que fazem menção ao "capital humano". Conforme o autor, por trás das ditas "aptidões naturais" há um fator fundamental que passa despercebido, mas que é "determinante socialmente dos investimentos educativos, a saber, a transmissão doméstica do capital cultural" (BOURDIEU, 2014, p. 81, grifo nosso). É sobre esse capital que tratamos então.

Para o autor, o capital cultural pode existir de três modos: o incorporado, o objetivado e o institucionalizado. O capital incorporado está diretamente ligado ao corpo e à assimilação de ideias e de práticas que pertencem somente àquele que a possui. Conforme o autor, esse capital "não pode ser acumulado para além das capacidades de apropriação de 
um agente singular" e, sendo assim, “depaupera e morre com seu portador" (BOURDIEU, 2014, p. 83) Essa incorporação exige do indivíduo, sobretudo, tempo de investimento sobre si mesmo: "o capital cultural é um ter que se tornou ser, uma propriedade que se fez corpo e tornou-se parte integrante da 'pessoa', um habitus" (BOURDIEU, 2014, p. 83). Sobre isso, pode-se citar o exemplo do investimento feito em educação: cada um dedica um tempo para si mesmo, constituindo-se em longos anos de trabalho intelectual que vão sendo incorporados ao próprio indivíduo.

Ao destacar como ocorre o processo de transmissão do capital incorporado, Bourdieu (2014) assinala que a mais eficaz ideologia se apresenta nessa espécie de capital. Segundo ele,

por um lado, a apropriação do capital objetivado [...] depende, principalmente, do capital cultural incorporado pelo conjunto da família - por intermédio, entre outras coisas [...] de todas as formas de transmissão implícita. Por outro lado, a acumulação de capital cultural - condição da acumulação rápida e fácil de toda espécie de capital cultural útil - só começa desde a origem, sem atraso, sem perda de tempo, pelos membros das famílias dotadas de um forte capital cultural; nesse caso, o tempo de acumulação engloba a totalidade do tempo de socialização. Segue-se que a transmissão do capital cultural é, sem dúvida, a forma mais dissimulada hereditária do capital (BOURDIEU, 2014, p. 84).

Para Bourdieu (2007), a apropriação da cultura iniciada no seio familiar e a aprendizagem da cultura que se inicia apenas com a entrada do aluno na escola implicam diferenças. A aprendizagem familiar da "cultura legítima" faz com que a criança tenha o contato direto com obras, objetos, cultos, práticas e pessoas que transmitirão tais habilidades. Estas crianças não precisarão adquirir esses conhecimentos quando entram na escola, que fornecerá apenas informações complementares. Ou seja, a escola, para elas, será tão somente uma extensão, pois não precisam se aculturar; desse modo, essa herança cultural familiar permite uma vantagem imensa 
em relação àquele que vem de uma família menos ou quase nada favorecida culturalmente. $\mathrm{O}$ "mundano" depara-se com a cultura por intermédio da escola, sendo facilmente ultrapassado pelo "douto", pois, para este, o conhecimento parece "natural" pelo fato de estar, desde o nascimento, em contato com todo um conjunto de bens culturais.

Por sua vez, em seu estado objetivado, o capital cultural tem retido no indivíduo as propriedades do capital cultural incorporado. $\mathrm{O}$ capital objetivado/materializado pode ser encontrado em quadros, livros, pinturas, etc.; por isso, esse tipo de capital só pode ser repassado ao outro em forma de materialidade. $\mathrm{O}$ repasse acontece pela aquisição do produto enquanto "materialidade" e, para isso, basta ter um volume razoável de capital econômico. Tal como afirma Bourdieu (2014, p. 85), “para possuir máquinas, basta ter capital econômico; para se apropriar delas e utilizá-las de acordo com sua destinação específica (definida pelo capital científico e tecnológico que se encontra incorporado nelas) é preciso dispor, pessoalmente ou por procuração, de capital incorporado".

Por último, Bourdieu (2014) se refere ao capital cultural em seu estado institucionalizado, ou seja, trata-se da objetivação do capital cultural sob a forma de diploma ou de outros títulos. Conforme o autor, o diploma confere ao seu portador uma certidão, um capital cultural juridicamente garantido e terá um valor maior ou menor no mercado de trabalho, segundo o curso, a carreira profissional, etc.

\section{Decifrando o sistema escolar e o capital escolar}

Conforme destaca Bourdieu (2014), o sistema escolar é uma instância de conservação social muito eficaz, pois ela não só valida as desigualdades sociais como também aprova a herança cultural de certos agentes como sendo um dom natural, uma aptidão inata. Esse sistema não leva em consideração que o capital cultural herdado da família corrobora de maneira direta para que esse agente seja o eleito, dentre os demais, 
como o(a) mais talentoso(a) e meritoso(a). Portanto, o sistema escolar é conservador e reprodutor, no sentido de que ele atua em conformidade com a cultura legítima e com os mecanismos de dominação, de eliminação e de seleção.

O desvelamento dos "mecanismos objetivos" que causam a exclusão, a eliminação, a expulsão ou o fracasso das crianças e dos jovens desfavorecidos socialmente é necessário, segundo o autor. Tais mecanismos podem ser analisados à luz da sociologia, ciência que possibilita compreender que o principal motivo do sucesso escolar, sempre atribuído às diferenças de dons, depende, segundo Bourdieu (2014), da posse do capital cultural.

Estudos desenvolvidos pelo autor desde os anos de 1960 têm demonstrado que a família tem um importante papel, qual seja, transmitir aos filhos "mais por vias indiretas que diretas, um certo capital cultural e um certo ethos, sistema de valores implícitos e profundamente interiorizados, que contribui para definir, entre outras coisas, as atitudes face ao capital cultural e à instituição escolar" (BOURDIEU, 2014, p. 46). Para Bourdieu (2014), quanto maior for o volume de capital cultural familiar, em seu sentido global/geral, maiores serão as chances de êxito escolar de seus descendentes. As crianças que acumulam êxitos escolares são favorecidas culturalmente desde o seio familiar e adentram no sistema escolar com certa familiaridade com a linguagem escolar, de modo que a facilidade com a aprendizagem parece ser ou é compreendida como natural.

Quanto às dificuldades no que se refere à aprendizagem, estas comumente são encontradas entre as crianças menos favorecidas culturalmente. Isso porque, conforme o autor, elas precisam se aculturar, pois "em virtude da lentidão do processo de aculturação, diferenças sutis ligadas às antiguidades do acesso à cultura continuam a separar indivíduos aparentemente iguais quanto ao êxito social e mesmo ao êxito escolar" (BOURDIEU, 2014, p. 47). As crianças e jovens menos favorecidos social, econômica e culturalmente, quando chegam ao universo escolar, são forçados/levados a decifrar 
uma série de códigos e de lógicas que não faziam parte do seu mundo social familiar. Acontece então o que Bourdieu chamou de violência simbólica, pois a grande maioria dos professores não está interessada em saber quais são as procedências de seus alunos.

Cobra-se que os alunos tenham um estilo elegante de falar, de escrever e até mesmo de se portar; que se mostrem sensíveis às obras da cultura legítima, que sejam intelectualmente curiosos, interessados $\mathrm{e}$ disciplinados; que saibam cumprir adequadamente as regras da "educação". Essas exigências só podem ser plenamente atendidas por quem foi previamente (na família) socializado nesses valores (NOGUEIRA; NOGUEIRA, 2014, p. 53).

Para Bourdieu, são as diferenças em capital econômico, cultural e linguístico adquiridos tanto no convívio familiar quanto no contato com pessoas que possam transmitir conhecimentos múltiplos e legítimos e a frequência a museus, a concertos e teatros alguns dos fatores determinantes que causam êxitos tanto no desempenho social quanto no desempenho escolar. Outro fator relevante refere-se à linguagem, ao modo ou à forma como ela é incorporada. Segundo Bourdieu (2014), a língua é o mais grave obstáculo cultural, apresentando-se muito severamente nos primeiros anos escolares. Ela impacta diretamente na assimilação dos conteúdos, sendo, por isso, mais complicada para as crianças das classes menos favorecidas.

A língua não é um simples instrumento, mais ou menos eficaz, mais ou menos adequado, do pensamento, mas fornece - além do vocabulário mais ou menos rico uma sintaxe, isto é, um sistema de categorias mais ou menos complexas, quer lógicas quer estéticas, parece função direta da complexidade da estrutura da língua inicialmente falada no meio familiar, que lega sempre uma parte de suas características à língua adquirida na escola (BOURDIEU, 2014, p. 51).

Ainda referente ao processo da herança cultural, o que se apresenta incorporado nos mais favorecidos socialmente, 
como a língua culta, o bom gosto, a arte, o lazer, os esportes mais "elitizados", entre outros, são adquiridos, conforme o autor, de maneira "osmótica". Isso "contribui para reforçar, nos membros da classe culta, a conviç̧ão de que eles só devem aos seus dons esses conhecimentos, essas aptidões e essas atitudes, que, desse modo, não lhes parecem resultar de uma aprendizagem" (BOURDIEU, 2014, p. 51).

Assim, Bourdieu (2011) destaca que a escola tende a classificar os seus "eleitos". Ela institui uma relação duradoura com eles e os legitima, porque os consagra. De acordo com Valle (2013, p. 423), “a escola é a única a deter completamente, em virtude da função própria, o poder de selecionar e formar, por uma ação que se exerce sobre todo o período da aprendizagem, aqueles aos quais ela confia a tarefa de perpetuá-la”. A escola, observada a partir da ótica bourdieusiana, perde, portanto, seu status outrora visto como democratizadora e transformadora. Isso também se observa na educação brasileira, pois ainda são poucos(as) os(as) estudantes das classes sociais populares que têm alcançado a educação superior. Uma medida que tenta democratizar e equiparar as dificuldades quanto ao acesso à universidade tem sido a adoção de políticas de ações afirmativas através do sistema de cotas nas universidades públicas. No entanto, deve-se observar que, por vezes, essas chances apenas têm prolongado e diluído o processo de exclusão ou de eliminação dos(as) estudantes menos favorecidos(as) social, econômica e racialmente. Logo, é preciso problematizar os desafios, as oportunidades e os avanços enfrentados com esta conquista por direitos através de políticas sociais - ainda mais quando se trata das mulheres negras.

\section{A interseccionalidade}

O debate, no meio feminista, em torno da questão de gênero tem sido amplo. De acordo com Piscitelli (2008), a partir do ano de 1990, esse debate, em nível internacional, é mobilizado a fim de contornar as múltiplas diferenças que se articulam ao gênero e permeiam o social. Não se discutia mais, 
somente as diferenças entre sexo e gênero, mas procuravam apresentar instrumentos que possibilitassem analisar e abranger as articulações das múltiplas diferenças e desigualdades. No centro desses debates, a fim de dar conta dessa problemática, várias autoras feministas apresentam suas conceituações. As autoras que propõem pensar essas problemáticas a partir da "interseccionalidade" ou das "categorias de articulação", segundo Piscitelli (2008) são Anne McClintock, Kimberlé Crenshaw e Avtar Brah. Para fins desta pesquisa, será levada em consideração apenas a proposta desenvolvida por Crenshaw.

Dentro dessa ótica de capturar as múltiplas diferenças impostas a pessoas do mesmo gênero, Kimberlé Crenshaw (2002) tem como proposta a interseccionalidade como instrumento de análise capaz de abranger a articulação entre as várias diferenças e desigualdades que se entrecruzam e que diferem no modo como cada uma vivencia a discriminação. Segundo a autora,

[...] todas as mulheres estão sujeitas ao peso da discriminação de gênero, também é verdade que outros fatores relacionados a suas identidades sociais, tais como classe, casta, raça, cor, etnia, religião, origem nacional e orientação sexual, são diferenças que fazem diferença na forma como vários grupos de mulheres vivenciam a discriminação (CRENSHAW, 2002, p. 173).

A interseccionalidade é, portanto, a maneira de apreender as consequências das interações que compõem uma série de diferenças como raça, classe, etnia, gênero etc., e que são ou se transformam em formas ou eixos de subordinação. Esses fatores relacionados ou eixos de subordinação participam da construção da inferiorização de umas e do privilégio de outras.

A interseccionalidade é uma conceituação do problema que busca capturar as consequências estruturais e dinâmicas da interação entre dois ou mais eixos da subordinação. Ela trata especificamente da forma pela qual o racismo, o patriarcalismo, a opressão de classe e outros sistemas discriminatórios criam desigualdades 
básicas que estruturam as posições relativas de mulheres, raças, etnias, classes e outras. Além disso, a interseccionalidade trata da forma como ações políticas específicas geram opressões que fluem ao longo de tais eixos, constituindo aspectos dinâmicos ou ativos do desempoderamento (CRENSHAW, 2002, p. 177).

Dessa maneira, as situações a partir das quais se estruturam as posições, em que se coloca uns em situação de subordinado(a) e a outros(as) como superiores, são as múltiplas formas como esses eixos se entrecruzam ou se interseccionam no meio social e produzem as subordinações, os desempoderamentos e as inferiorizações. Crenshaw, para exemplificar essa "interseção" no meio social, faz uso da imagem das avenidas das cidades: nessas avenidas, segunda a autora, transita um "eixo de opressão", e, em seus cruzamentos, encontram-se "pessoas" que enfrentam os fluxos e que, ao se encontrar umas com as outras, oprimem aquele(a) que se encontra no cruzamento. Conforme a autora, são essas avenidas "que estruturam os terrenos sociais, econômicos e políticos. É através delas que as dinâmicas do desempoderamento se movem. Essas vias são por vezes definidas como eixos de poder distintos e mutuamente excludentes" (CRENSHAW, 2002, p. 177).

São, portanto, para Crenshaw, vários fatores que agem conjuntamente sobre o gênero, o que implica redobrada atenção no momento de analisar as formas de discriminação, como o contexto social, as políticas, as práticas ou as ações dos indivíduos/agentes, além de como essas formas/práticas se estruturam na sociedade, produzindo e reproduzindo as dominações e subordinações.

\section{O espaço familiar como transmissor da herança cultural escolar}

Nas trajetórias de vida escolar e universitária das jovens mulheres negras cotistas que vamos apresentar, ficará explícita 
a transmissão da herança cultural e escolar no contexto familiar, ou seja, que elas são herdeiras de um processo de transmissão do capital cultural e escolar, o que torna suas condições de aprendizagem mais facilitadas. Ou seja, elas dispuseram, no seio familiar, de um conjunto de predisposições e de présaberes que contribuem para o sucesso escolar. As evidências desse processo de transmissão ficam claras, por exemplo, nos relatos em que se referem à frequência com que os pais as acompanharam nas tarefas escolares ou aos momentos em que estes contaram e leram histórias (o que também indica possuírem livros em casa), como se verá a seguir.

Cabe lembrar que o acompanhamento dos pais nas tarefas escolares realizadas no seio familiar desencadeia aptidões que se aproximam muito da cultura escolar. A herança cultural e escolar favorece e incide diretamente nas trajetórias individuais, possibilitando condições e disposições favoráveis ao bom desempenho nos estudos. Por isso, através das histórias de vida relatadas, foi possível avaliar a relação com o saber no seio familiar e o sucesso quanto à aprovação no vestibular, permitindo-nos perceber que as trajetórias escolares e universitárias das jovens são consequência de percursos estrategicamente orientados pelas famílias na realização de investimentos educacionais e na orientação de valorização da cultura escolar.

\section{Perfil 1: estudante do curso de Biologia, 23 anos de idade $^{3}$}

3 Entrevista realizada em abril de 2016

"Eu estou na universidade porque eu acho, sim, importante ocupar esse lugar dentro da universidade" (informação verbal).

A estudante que aqui apresentamos é filha única e natural da capital catarinense. Seus pais são professores universitários: a mãe possui doutorado em Educação e o pai tem doutorado em Educação Física. Começando pela descrição da família, tem-se um quadro atípico da grande maioria das famílias brasileiras, considerando-se o grau de 
escolaridade dos pais. Essa configuração familiar foi um caso específico, em que o fator capital escolar ficou acima do que normalmente se encontra nas famílias populares brasileiras. Observando a trajetória da jovem, vai-se explicitar como isso pode ou não ter influenciado sua vida.

O âmbito escolar foi praticamente o lugar onde esta jovem passou a maior parte da sua vida, pois começou a frequentá-lo desde o berçário. Ela destacou ter sempre estudado em escolas públicas, porque os pais acreditavam que se tratava de um ensino adequado: "os meus pais sempre acreditaram no sistema de ensino público, que era onde eles trabalhavam também" (informação verbal). $\mathrm{O}$ fato de os pais serem professores deve ter influenciado no bom desempenho da estudante durante sua trajetória escolar, o que se comprova com seu comentário de que sempre foi incentivada nas atividades escolares: "eu sempre fui muito incentivada à leitura, à escrita, essas coisas, então era uma criança que não precisava ter feito a primeira série, eu já era alfabetizada" (informação verbal). Ela estudou na mesma escola até a quarta série, em um bairro de Florianópolis; a quinta série foi em outro colégio da mesma cidade. A sexta série foi cursada na cidade de São Bento do Sul, pois seu pai foi aprovado em um concurso público e a família acabou se mudando para essa cidade.

4 A estudante se refere ao Colégio público Lauro Müller, localizado em Florianópolis, em Santa Catarina (SC).
[...] daí a gente foi morar numa cidade pequena, de colonização alemã... (risos). Então, eu me sentia um "bichinho exótico", de chegar ao ponto de uma vez um colega, nessa escola, me perguntar: "Mas em Florianópolis tem pessoas igual a você andando na rua?", Como quem diz, "mas existem pessoas negras em Santa Catarina, não é só gente branca?”, nesse sentido! $\mathrm{E}$ todas aquelas brincadeiras que vem junto né, cabelo, cabelo ruim, de ficar brincando de fazer como se tivesse um isqueiro de baixo do cabelo, tipo pra botar fogo, então, tudo isso eu passei durante esse um ano e meio que a gente morou lá.

Quando eu cheguei na escola, tinham duas turmas de sexto ano. Eu fiz a quinta série no Lauro Müller ${ }^{4}$ e, no sexto ano, eu mudei pra esse colégio. No dia [em] que eu cheguei, já tinham começado as aulas e uma 
das moças da escola, que trabalhava na secretaria, me levou até a sala de aula que eu ia ficar. Só que o meu nome acabou saindo na chamada da outra turma. Olha só como isso marca né, é uma coisa que daqueles anos todos que eu estou guardando ainda hoje, assim, ela não chamou meu nome, ela perguntou, "Alguém não tá na lista?" E eu levantei a mão, e ela disse, "claro, tinha que ser burra, entrou na sala errada ainda!" (informação verbal).

Ao se examinar a fala acima, destacam-se dois aspectos: a discriminação racial e a relação pedagógica em seu sentido de "julgamento professoral". Essa relação pedagógica se legitima na autoridade que o(a) professor(a) exerce sobre o(a) aluno(a) emitindo seus julgamentos, implicando em violência simbólica. Como a jovem destaca, "daqueles anos todos que eu estou guardando ainda hoje", de forma que -o "julgamento" emitido pela professora exemplifica o trabalho de inculcação que produz o(a) professor(a) na vida dos seus estudantes, seja qualificando ou desqualificando. Afirmam Bourdieu e Passeron (2008, p. 43) que,

numa formação social determinada, a força propriamente simbólica das sanções físicas ou simbólicas, positivas ou negativas, juridicamente garantidas ou não, que asseguram, reforçam e consagram duravelmente o efeito de uma ação pedagógica, é tanto maior quanto elas se aplicam a grupos ou classes mais dispostos a reconhecer a autoridade pedagógica que os impõe.

Nota-se, quanto ao racismo nas relações sociais, que a estudante não se vê representada e, pior que isso, não encontra respeito recíproco, convivendo em um contexto em que a maioria das pessoas é de origem alemã e as piadas com relação a seu cabelo são constantes. Assim como o racismo fica expresso no meio escolar, através da professora, ele se faz presente em todas as esferas, nas relações e práticas sociais de forma estruturada, confirmando o fato de que o campo educacional também é local de tais práticas. $\mathrm{O}$ racismo e a discriminação 
têm aparecido recorrentemente nesse espaço, principalmente quando o(a) professor(a) faz uso de sua autoridade pedagógica, de sua autonomia docente para agir sobre o aluno. Segundo Gomes (2005), a autonomia do professor não está somente atrelada às escolhas metodológicas, à autoridade no agir e às escolhas das temáticas; ocorre que a autonomia do professor e a questão racial estão atreladas à

[...] nossa postura ética diante da diversidade étnicocultural e das suas diferentes manifestações no interior da escola. Que tipo de profissionais temos sido? A educação carece de princípios éticos que orientem a prática pedagógica e a sua relação com a questão racial na escola e na sala de aula (GOMES, 2005, p. 149).

Observa-se essa questão colocando em evidência o segundo aspecto, o da relação pedagógica em seu sentido de “juízo professoral”, pautando-se nos estudos de Bourdieu (2014) para refletir sobre isso. Conforme o sociólogo, "as classificações que os professores produzem cotidianamente na e pela prática, e que são produzidas e reproduzidas pelo sistema escolar, impõem às formas que organizam o pensamento e a expressão da classe dominante" (BOURDIEU, 2014, p. 208-209).

Como se pode notar, outras questões aparecem relacionadas ao gênero, como o racismo e a discriminação. Para além do modo como o professor estrutura seu julgamento, segundo a origem social, a profissão dos pais, a aparência e a desenvoltura do(a) aluno(a), está o racismo, que também é amparado nas organizações e se estrutura pelos interesses da classe dominante. Acrescentam-se ao racismo patriarcal outros mecanismos de hierarquização e de subordinação que, junto às desigualdades e às iniquidades, tomam várias expressões, tendo a raça como decisiva das disposições de gênero vividas sob regime heteronormativo, marcas estas fortalecidas ou desqualificadas por diversas condições individuais ou coletivas (CRENSHAW, 2002). Essas desigualdades de tratamento ou de práticas discriminatórias têm por base a diferença do outro e estão permeadas de "estereótipos e representações 
negativas de grupos minoritários. Esses estereótipos culturais tendem a se autoconfirmar e acabam limitando as aspirações e as motivações, neste caso, das pessoas não brancas" (HASENBALG, 2006, p. 261).

Quando a jovem retornou a Florianópolis, matriculou-se no colégio que frequentava antes de ir para São Bento do Sul:

Voltei no meio do ano, daí voltei pra esse colégio que eu tinha estudado anteriormente, que era o Lauro Müller.Deu uma relaxada [...].É muito engraçado essa questão da identificação, [..] ter pessoas semelhantes a você é importante. O pessoal diz, "ah não, isso é um exagero!”. Gente, não! Vocês não têm noção de qual é o alívio você chegar numa escola e ver que você não é a única criança negra lá dentro (informação verbal).

Assim como em outros casos que foram apresentados aqui, neste também aparecem a expressão "se ver representado(a)" e a questão da identidade. Ver o(a) semelhante e se sentir representado(a) é fundamental para a construção da identidade, que se faz nas diferenças. O problema está nas relações sociais que demarcam as diferenças "simbólicas" e as classificam como boas ou más, mais ou menos belas, mais ou menos inteligentes e assim sucessivamente. Criam-se, assim, grupos de opostos para consumar a exclusão. Conforme Hall e Woodward (2004, p. 39-40),

As identidades são fabricadas por meio da marcação da diferença. Essa marcação da diferença ocorre tanto por meio de sistemas simbólicos de representação quanto por meio de formas de exclusão social. A identidade, pois, não é o oposto da diferença: a identidade depende da diferença. Nas relações sociais, essas formas de diferença - a simbólica e a social são estabelecidas, ao menos em parte, por meio de sistemas classificatórios. Um sistema classificatório aplica um princípio de diferença a uma população de forma tal que seja capaz de dividi-la em ao menos dois grupos opostos - nós/eles; eu/outro.

Acrescenta-se a isso a discriminação racial, que se estrutura justamente nessas aporias de sistemas 
classificatórios, de dominação, de exclusão, de subordinação, etc., pois fazer distinção a partir da diferença física do outro é discriminação racial.

Apesar dos impasses, assim que terminou o Ensino Fundamental, a estudante deu continuidade ao Ensino Médio, o qual realizou no colégio Henrique Stodieck. Depois de concluído esse nível de ensino, ela se organizou para fazer o concurso vestibular:

5 Universidade do Estado de Santa Catariana.

6 Pepê e Neném são uma dupla de cantoras negras brasileiras formada pelas irmãs gêmeas idênticas Potiara da Silva Oliveira e Potiguara da Silva Oliveira.
[...] não fiz cursinho, fiz ensino público. $\mathrm{O}$ primeiro vestibular fiz para Artes Visuais na UDESC. ${ }^{5}$ Passei e não fui fazer. Fiz pra Biologia, na UFSC, e não passei. Não fiz por ações afirmativas, [porque] eu fiquei com vergonha de fazer. Tá, o meu primeiro vestibular... Aí fui trabalhar. Eu falei "ah! não quero esse curso de Artes Visuais”, então não vou fazer, prefiro ir trabalhar e juntar um dinheiro e me preparar pro vestibular que vem, do que ficar fazendo um curso que eu não quero (risos).

No ano seguinte, eu entrei pra Biologia. Fiz [vestibular] pra Biologia e Medicina Veterinária e passei nos dois. Fiz por ações afirmativas na UDESC, pra Veterinária, e fiz por ações afirmativas, na UFSC, pra Biologia. Aí vim fazer Biologia aqui na federal (informação verbal).

Seu ingresso foi no ano de 2012, quando deu início ao curso de Biologia, porém concluiu somente até a sétima fase do curso, desistindo dele no final do ano de 2015.

A oportunidade de entrar na universidade por meio da modalidade das ações afirmativas nem sempre tem sido tranquila para seus optantes. O racismo, os estereótipos e as discriminações atribuídas aos estudantes que entram por cota racial são frequentes. A estudante relata o apelido que recebeu durante o "trote" universitário: "No trote, o meu apelido de caloura, junto com a outra menina negra, era "Pepê e Neném"... (informação verbal).

Mesmo que tenha passado algum tempo sem se identificar como "cotista", pois tinha receio de que poderia ser mais discriminada ainda, a jovem analisa como positivas e necessárias as ações afirmativas: 
[...] entrei por ações afirmativas, o que foi ótimo!

Então, ocupei uma vaga que era minha e "vocês todos puderam entrar ainda", "olha só que maravilhoso não é?”.Nnão estou ocupando vaga de ninguém não; entrei por uma vaga que era minha, por um processo seletivo, então está tudo ótimo, todo mundo feliz! (informação verbal)

A militância da jovem em atividades e projetos sociais explica boa parte da forma como ela apresenta seu ponto vista sobre vários assuntos, como as ações afirmativas e os movimentos negro e LGBTTT (lésbicas, gays, bissexuais, travestis, transexuais e transgêneros). Ela tem participado de vários projetos como ativista, como o que envolve artes e orientação sexual em algumas escolas, além de integrar o Núcleo de Estudos Afro-brasileiro (NEAB) da UDESC. A seu ver, esse engajamento é consequência de sua criação, pois "O meu pai, tinha projetos sociais no Morro da Caixa e no Morro do Mocotó, então eu cresci lá” (informação verbal).

A atividade de militante/ativista em núcleos e em outros projetos sociais tem direcionado sua atuação para outra área profissional. No final do ano de 2015, quando já havia completado sete semestres do curso de Biologia, a jovem fez novamente o concurso vestibular na UDESC, novamente para o curso de Artes Visuais, no qual passou. Atualmente, ela faz esse curso, que a tem colocado em atividades conectadas à esfera das artes e a inspirado à militância nos movimentos negros.

Ao se referir ao mercado de trabalho, ela destacou que deseja, no futuro, ser professora universitária, pois tem verificado a ausência de professores(as) negros(as). A militância fica mais evidente na fala a seguir, quando ela afirma ter se inspirado na mãe para tratar de assuntos que abordam a questão da sexualidade:

A minha briga no mercado de trabalho é dentro da universidade. Então, eu entrei pra artes, que era uma coisa que eu já trabalhava, porque me dá prazer trabalhar com artes. Eu estou puxando mesmo é licenciatura, eu quero é ir pra área da educação. 
Eu trabalho com sexualidade de gênero. [Primeiro] porque a minha vivência desde os 14 anos, a primeira pessoa com quem eu namorei, foi uma menina, então... É a área na qual eu trabalho e me permite fazer um trabalho bem legal, nas escolas, em toda essa questão, e aí daqui pra frente a minha intenção é juntar toda essa questão, além da sexualidade, de gênero, com a questão étnica.

Sabe, essa questão de [que] você não se vê representada, isso te desanima muito. Você tem três opções se você é mulher negra hoje no Brasil, você pode ser empregada doméstica, você pode ser dona de bar, ou você pode ser bonita e casar com um cara rico, segundo a Globo. Essas são as três opções se você é uma mulher negra no nosso país hoje. Então toda essa questão de se ver representada em outras pessoas [...] eu me vi representada na minha mãe.

A minha mãe, quando ela se formou... O mestrado dela foi sobre violência contra criança e adolescentes. Hoje ela trabalha com orientação sexual na formação de professores.

Eu poderia estar fazendo outras coisas, quero aproveitar esse espaço que me foi negado, a tanta gente antes de mim também, foi negado a todas as minhas tias, que não puderam estar dentro da universidade. Um espaço que foi negado pra gente durante muito tempo e não [era] pra gente há 30 anos atrás, é pra gente da minha família, ali oh! 10 anos atrás, sabe. Fazer as pessoas entenderem, as pessoas brancas entenderem, de como elas são privilegiadas.

A vontade está ali, se tivesse apoio financeiro, tava fazendo alguma coisa. Muitas das pessoas que estão lá, que moram no morro, tem que manter uma casa com cinco, seis pessoas às vezes. E quem está na universidade é quem tem já, ou teria condições de estar trabalhando pra ajudar numa renda de no mínimo 1.000 reais. 1.000 reais, não é o dinheiro que aquela família pode dispensar, não dá pra trocar aqueles 1.000 reais por uma bolsa de 400 reais (informação verbal).

Fica evidente que a estudante discute assuntos como, por exemplo, as ações afirmativas, racismo, discriminação, assuntos que englobam a sexualidade, o gênero, e que foram sendo apropriados quando participou de atividades desenvolvidas outrora pelo pai e, mais recentemente, pela mãe. 
Perfil 2: estudante de Design Gráfico, 22 anos de idade $^{7}$

"Eu sabia que a educação era a saída... eu me imagino uma mulher de muito sucesso em cargos de chefia" (informação verbal).

A jovem entrevistada nasceu em uma cidade ao norte de Minas Gerais, mas, quando tinha um mês de vida, seus pais se mudaram para uma cidade localizada na região nordeste do Estado de Santa Catarina. Ela tem três irmãos. Sua mãe possui graduação em História, área na qual é professora, e o pai, que completou o Ensino Fundamental, é metalúrgico. Destaca-se, assim, o capital escolar da família, sobretudo por a mãe ser professora. A trajetória escolar de êxito da estudante se caracteriza, então, de certa maneira, por ela ter presente na família o capital escolar considerável, como se poderá observar na sequência.

A inserção da jovem na escola teve início na préescola: "prézinho, primeira série, segunda série... e, desde sempre, a minha mãe estimulou muito a educação, sempre contava histórias pra dormir, colocava giz de cera, caderninho pra passar por cima das letrinhas, ligar os pontinhos..." (informação verbal).

Com relação à aprendizagem, a jovem enfatiza mais a educação recebida por meio das estratégias educacionais desenvolvidas pela mãe, o que parece ter marcado bastante sua vida. Quando chegou o momento de cursar o Ensino Médio, a mãe também foi estratégica, pois incentivou a jovem a se inscrever na escola estadual e, ao mesmo tempo, prestar concurso para o Instituto Federal. Como conseguiu aprovação no Instituto, ela fez o Ensino Médio Técnico em Sistemas da Informação. Logo que terminou, ela prestou concurso vestibular para Design Gráfico em três universidades: "eu fui prestar o vestibular na UFSC, na UFPR ${ }^{8}$ e na UDESC. Eu consegui passar na UFSC, entrei por cotas" (informação verbal).

A jovem entrevistada iniciou o curso em 2011. Logo que essas jovens entram na universidade, elas precisam se
Revista Grifos 209

7 Entrevista realizada em março de 2016.
8 Universidade Federal do Paraná 
sustentar financeiramente e se manter na universidade. Essa tem sido uma das preocupações dos estudantes com baixa renda, quando não podem contar com a ajuda dos pais. A falta de recursos pode prejudicar o andamento neste processo de ter que se sustentar: "eu passei, fiz a matrícula. Aí, na primeira fase, eu conheci uma professora que foi como uma mãe, ela me deu uma bolsa de pesquisa e extensão e eu fui indo assim, sempre tive bolsa na UFSC. Porque a minha mãe não podia ficar pagando aluguel pra mim" (informação verbal). Contudo, ela procurou se beneficiar das outras formas, no sentido de se manter financeiramente, realizando estágios remunerados: "fiz alguns estágios aqui na UFSC e fiz estágio também no Estado" (informação verbal).

Novamente pesa o fator econômico. As universitárias desprovidas de capital financeiro precisam conciliar alguma atividade laboral para complementar a renda, o que torna a vida mais laboriosa, esforçada, sobrecarregada para essas alunas, diferentemente daqueles que possuem capital financeiro e todo o tempo para se dedicar aos estudos. No entanto, tem-se percebido que essa dupla atividade, o trabalho e a academia, não tem sido impedimento para as jovens concluírem o curso nos prazos regulamentares. Pelo contrário: elas vêm demonstrando grande esforço e, mesmo que ocorram reprovações em algumas disciplinas, têm procurado superar essas dificuldades.

A entrada dessas jovens na universidade por meio das ações afirmativas as tem colocado em situações constrangedoras. Esse é um dos aspectos em comum entre as entrevistadas. Contudo, a presença do(a) estudante cotista tem dado a oportunidade para outros alunos(as) emitirem suas opiniões, principalmente sobre os(as) estudantes negros(as). $\mathrm{O}$ primeiro dia da jovem na universidade, na recepção dos calouros, ficou marcado por esse tipo de emissão de valores; segundo ela, "os calouros têm nome, e eu era a Globeleza três, a terceira geração da Globeleza, porque é a única figura pública que tem de representação negra" (informação verbal). Nota-se como os(as) estudantes buscam "representar" a mulher 
negra. Estereotipar a mulher negra (nesse caso, a estudante) a uma representação de símbolo sexual do carnaval brasileiro é negar que as mulheres negras também representam mulheres intelectuais e que também ocupam lugares de prestígio social como qualquer outra mulher.

Na perspectiva de Fanon (2008, p. 53),

O homem é movimento em direção ao mundo e ao seu semelhante. Movimento de agressividade que engendra a escravização ou a conquista; movimento de amor, de doação de si, ponto final daquilo que se convencionou chamar de orientação ética. Qualquer consciência é capaz de manifestar, simultânea ou alternativamente, essas duas componentes (informação verbal).

Ora, chega-se a conjecturar que todo homem ou toda mulher, para ser ético, deveria, ao se movimentar, conforme Fanon (2008), partir da receptividade recíproca, da igualdade e da justiça, porém, muitos agem na direção contrária, isto é, engendram a hierarquia, a subalternização do(a) outro(a). É assim que as discriminações e o racismo agem, por meio de mecanismos seletivos de classificação e por barreiras em todas as esferas das relações sociais.

A estudante se mostrou otimista ao considerar o mercado de trabalho como uma possibilidade de ascensão social. No momento em que concedeu a entrevista, ela trabalhava na área de design, tendo sido contratada graças ao estágio: "a área que eu estou hoje, nem sei como eu consegui chegar lá, porque eu sou diretora de arte numa agência de publicidade aqui em Florianópolis. Nessa área [em] que eu estou, já é um desafio por ser mulher, e por ser negra também" (informação verbal). Tratava-se então de um momento importante, pois ela estava terminando a graduação e conseguiu logo se inserir no mercado de trabalho, embora essa vaga ainda não contemple o que ela realmente almeja: "eu me imagino uma mulher de muito sucesso, em cargos de chefia” (informação verbal).

Referindo-se à discriminação racial, a estudante declara que seria importante as famílias trabalharem a valorização da 
beleza negra, pois, segundo ela, isso ajuda, em muitas situações, a não relevar a discriminação racial. Nas palavras dela:

A minha mãe ela sempre reforçou muito isso da autoestima negra. Tem muito negro que não tem autoestima boa, porque você não vê, na novela, o negro com papel de rico, negro é sempre... "é empregada"... E o negro, quando aparece na publicidade, não é [a] negra de verdade, é a mulher negra de cabelo liso, rosto fino, nariz fino, boca fina. Então você tem uma negra branca, porque negra é só a cor da pele, não são os traços reais.

Então, desde pequena, ela [a mãe] comprava boneca negra pra mim, lia historinhas, fábulas com pessoas negras, então sempre tive essa figura muito marcante assim, de realmente ter a beleza negra, sempre fui muito resolvida em relação a isso (informação verbal).

9 Entrevista realizada em maio de 2015

\section{Perfil 3: estudante do curso de Psicologia, 22 anos} idade $^{9}$

"E quando abro a listagem de aprovados vejo o meu nome na lista! Uma sensação indescritível, um misto de missão cumprida com alívio, felicidade de me inserir no mundo acadêmico!" (informação verbal).

Natural de uma cidade próxima ao litoral Catarinense, a jovem é filha única. Os pais estão aposentados; a mãe é graduada em história e o pai era policial militar. Ambos se separaram quando a jovem tinha 10 anos de idade.

A partir dessa breve descrição sobre a família, buscase ressaltar o capital escolar que a mãe da jovem possui: a graduação em história. A posse de um diploma, além do seu valor no mercado de trabalho, tem também um valor simbólico e cultural, pois, nas famílias em que os pais ou um deles são 
possuidores do capital escolar, certamente se lutará para que os filhos, no mínimo, tenham um diploma superior, dado a relação que possuem com os saberes escolares.

A inserção da jovem no contexto escolar aconteceu bem cedo, aos seis meses de idade, mas logo se dissipou. Ela não permaneceu nesse espaço institucional, de cunho público, por muito tempo, dado que adoeceu, vindo a ser cuidada por uma madrinha até completar três anos de idade. Dessa idade em diante, sua mãe lhe colocou em colégios particulares até sua entrada na universidade, passando por diferentes colégios durante a creche, a pré-escola e a primeira série do primário, até ingressar no qual estudou por mais tempo: "eu fui para o colégio Adventista, [onde] eu fiquei da segunda série até o primeiro ano do Ensino Médio" (informação verbal).

Sempre que precisou de ajuda quanto às questões escolares, o apoio veio de sua mãe: "nas tarefas, minha mãe sempre me deu auxílio para correção ou então [para] tirar minhas dúvidas... Porém, não tinha o hábito de fazermos juntas. Era apenas nos momentos que eu precisava" (informação verbal).

Quando ela chegou à adolescência, resolveu experimentar o mundo do trabalho para adquirir experiência, pois a parte econômica sempre foi custeada pela mãe:

Desde os 15 anos, eu havia planejado fazer estágio com intuito de ter minha independência financeira, e assim eu fiz. Fui atrás, pesquisei, fiz entrevistas e passei na minha primeira experiência profissional. E aí eu fiquei um ano e meio como auxiliar administrativo em uma empresa, coisa da minha cabeça porque minha mãe nunca disse pra mim ir trabalhar, que eu tivesse que ajudar em casa. Graças a Deus, ela sempre foi minha parceira né, sempre me apoiou nos estudos. Porém, [quando] chegou no $3^{\circ}$ ano do Ensino Médio, eu tinha muitas aulas à tarde e tinha que me dedicar exclusivamente aos estudos que antecipavam a prova do vestibular. Tive que sair do estágio e ficar apenas com os estudos. Era isso que eu queria, entrar na faculdade de Psicologia pela federal. Então, eu tinha que bancar essa escolha! (informação verbal). 
Nesse terceiro ano do Ensino Médio, a jovem mudou de colégio com o objetivo de acelerar os estudos, pois estava se preparando para o vestibular:

Eu fui para o colégio Decisão e me formei lá. E logo que eu me formei eu passei na UFSC. Lembro como se fosse ontem, esse foi um dos vestibulares em que mais demorou para sair o resultado. Estávamos praticamente em fevereiro e o resultado ainda não havia saído. Eu já estava fazendo novos planos, não estava "crente" que ia passar. Já tinha todo o plano $B$ na mente, que seria arranjar um emprego, me matricular em um cursinho para tentar o vestibular novamente. Sempre fui de me planejar e ter várias opções na mente. De repente, escuto no jornal que o resultado saiu, rapidamente fui acessar o site e quando abro a listagem de aprovados vejo o meu nome na lista da $1^{\circ}$ chamada, isso foi fantástico (informação verbal).

A jovem iniciou a graduação em Psicologia no ano de 2010. A passagem pelo curso, para a jovem, além de ter sido um investimento pessoal em capital cultural, possibilitoulhe ver o mundo e as relações sociais de outra maneira: "eu me tornei muito mais crítica, minha capacidade de observar o ser humano, não só o que a gente vê, mas o que está por trás daquilo que muitas vezes não está visível né" (informação verbal). Acrescentaram-se a essas experiências vividas outros momentos de reflexão experimentados quando a jovem realizou os estágios obrigatórios. Na graduação em Psicologia, é necessário escolher, dentre quatro "áreas gerais", duas, de preferência do(a) estudante.

10 O Centro de Atenção Psicossocial (CAPS) realiza atendimentos nas áreas de psicologia e de psiquiatria. Mais informações estão podem ser encontradas em: <https:// www.hagah.com.br/centro-deatencao-psicossocial-caps-ruibarbosa-713>. Acesso em: 02 abr. 2016.
Eu fiz a Clínica e a Organizacional. A Organizacional, numa empresa na UFSC, [de] engenharia elétrica, durante um ano. E a outra eu fiz no CAPS. ${ }^{10}$ Foi no último ano da faculdade. Cada graduando deveria se inserir em um campo de estágio, porém, na época, as vagas estavam escassas. Minha última tentativa de vaga em estágio Clínico foi para um estágio no CAPS AD (Centro de Atenção Psicossocial Álcool e Drogas). E consegui! Foi um mundo totalmente novo e diferente. Um ano mais bem aproveitado em termos 
de conhecimentos na minha vida. Além de trabalhar com psicologia clínica, lá eu tinha a oportunidade de trabalhar com grupos psicoterapêticos, grupos multidisciplinares e saúde pública. Lidava com pacientes usuários de drogas pesadas, pessoas em situação de rua, pacientes em crise, pacientes em abstinência e todas as vulnerabilidades existentes na vida de um ser humano. Essa experiência, trouxe muita bagagem para minha vida, e me fez enxergar situações banalizadas pela sociedade. Cresci muito, e tenho muito orgulho e gratidão de ter experienciado essas questões! (informação verbal).

Como ela destaca, os estágios foram importantes, e as experiências lhe trouxeram mais conhecimento para a vida. Contudo, ao se referir ao mercado de trabalho, a estudante coloca que a inserção na área de Psicologia não é tão simples assim. Ela ressalta que seria mais fácil se tivesse, na família, alguém reconhecido no mercado atuando na área, ou se as condições econômicas fossem favoráveis para poder montar o próprio consultório. Assim, ela não estaria enfrentando dificuldades para conseguir um emprego na área depois de formada: "aí que a gente vê as milhares de coisas que a gente tem que pagar pra poder conseguir né" (informação verbal). Outro problema enfrentado no mercado de trabalho é a discriminação racial. Disse só ter notado a existência do racismo quando foi procurar emprego na área: "hoje que eu estou formada, percebo que é difícil ingressar no mercado como psicóloga. Porque agora que eu estou tentando me inserir, eu vejo que é complicado... É difícil a questão racial na hora de uma entrevista. A gente já vê a forma de te olharem... por eu ser negra" (informação verbal).

Aqui está em jogo a questão racial e o reconhecimento do diploma no mercado de trabalho. $\mathrm{O}$ não reconhecimento e a desvalorização do diploma, no mercado de trabalho, ligado à discriminação racial, tem encontrado respaldo nas organizações empregatícias quando estas negam chances de contratação ao(à) detentor(a) do diploma de Ensino Superior. Conforme Bourdieu (2007, p. 127), "fora do mercado propriamente escolar, o diploma vale o que, do ponto de vista econômico e 
social, vale seu detentor; neste caso, o rendimento do capital escolar depende do capital econômico e social que pode ser reservado à sua valorização". Na sociedade brasileira, em que o racismo opera por vezes velado, por vezes explícito, que valor tem o detentor de um diploma superior se for negro ou negra? As chances de alcançar uma posição de destaque não estão em patamar de mesma igualdade e oportunidade, nem para homens e mulheres, muito menos quando se releva a questão étnico-racial e, pior ainda, quando recai a comparação entre as mulheres negras e brancas - a menos que a contratação seja por processo de seleção via concurso público.

\section{Considerações finais}

Ao finalizarmos este artigo, gostaríamos de levantar alguns pontos centrais de quando se desenvolve um estudo sobre as relações étnico-raciais, principalmente quando se trata das mulheres. Nesse sentido, ressaltamos que o racismo, a questão de gênero, a democratização do ensino superior por meio das ações afirmativas e as "diferenças" que compõem o contexto universitário merecem uma perspectiva reflexiva, sobretudo sobre a questão da "reprodução social" tal qual apontou Pierre Bourdieu, principalmente quando se considera que o acesso à educação superior, por meio dessa política, tem sido a "oportunidade" para as jovens no caso aqui em questão.

As ações afirmativas têm possibilitado uma inserção maior das diferenças sociais, culturais e étnicas nas universidades. Essas diferenças, todavia, têm dado condições para novas relações no campo universitário, isso em sentido ambíguo, pois observou-se que tanto enriquece as práticas sociais e seus ambientes, como muitas vezes discrimina. Essas práticas sociais e culturais, bem como os discursos, muitas vezes, são atravessados por perspectivas de cunho positivo e negativo. Quando se fala no aspecto positivo, foi por analisar que as novas relações sociais, no campo universitário, têm possibilitado um entrelaçamento de culturas que impactam os sujeitos e a superação, por vezes, das muitas diferenças e desigualdades. Porém, nesse jogo da inclusão e das diferenças, 
ressalta-se o ponto "negativo" em que as opressões se "chocam"

e se entrecruzam nas mais diferentes formas de subordinações, discriminações e dominações.

Assim, a análise dessas três trajetórias de vida escolar e acadêmica permitiu apresentar diferentes interpretações quanto aos relatos feitos, no que se refere ao racismo, à condição de ser mulher negra e também à questão da herança cultural escolar que essas jovens tinham em suas famílias. Como é possível notar nos relatos das entrevistas, as estudantes narraram ter sofrido discriminação, mas, ao mesmo tempo, afirmaram que essa questão não lhes afetava tanto, porque seus pais tinham trabalhado muito a questão da identidade negra durante a infância; por conta disso, elas sabiam lidar com ela. Quando questionadas sobre o que esperavam do mundo profissional, as entrevistadas destacaram a falta de representatividade das mulheres negras nos espaços que elas escolheram por profissão no caso, a Biologia, o Design Gráfico e a Psicologia. Nesse contexto do relato das estudantes, o fator "gênero" não lhes aparece como problema, mas essas jovens ainda acham/acreditam que enfrentarão problemas com o racismo e a discriminação no âmbito da esfera profissional. Porém, para elas, o gênero não se articularia como obstáculo.

\section{Referências}

BOURDIEU, P. A distinção: crítica do julgamento. Porto Alegre: Zouk, 2007.

BOURDIEU, P. Escritos de Educação. Organização de: Maria Alice Nogueira e Afrânio Catani. Petrópolis: Vozes, 2014.

BOURDIEU, P. Razões práticas: sobre a teoria da ação. Campinas, SP: Papirus, 2011.

BOURDIEU, P.; PASSERON, J. C. A reprodução: elementos para uma teoria do sistema de ensino. Petrópolis: Vozes, 2008.

CRENSHAW, K. Documento para o encontro de especialistas em aspectos da discriminação racial relativos ao gênero, Estudos feministas, Florianópolis, v. 10, n. 1, p. 171-189, 2002.

FANON, F. Pele negra máscaras brancas. Salvador: EDUFBA, 2008. 
GOMES, N. L. Educação e relações raciais: refletindo sobre algumas estratégias de atuação. In: MUNANGA, Kabengele (Org.).

Superando o racismo na escola. Brasília: Secad, 2005. p 143-154.

HALL, S.; WOODWARD, K. Identidade e diferença: a perspectiva dos estudos culturais. Petrópolis: Vozes, 2004.

HASENBALG, C. Entrevista com Carlos Hasenbalg a Antonio Sérgio Alfredo Guimarães. Tempo social: revista de sociologia da USP, São Paulo, v. 18, n. 2, p. 259-268, 2006.

NOGUEIRA, M. A.; NOGUEIRA, M. M. Bourdieu \& a Educação. Belo Horizonte: Autêntica, 2014.

PISCITELLI, A. Insterseccionalidades, categorias de articulação e experiências de migrações brasileiras. Sociedade e cultura, v. 11, n. 2, p. 263-274, jul./dez. 2008.

VALLE, Ione Ribeiro. O lugar da educação (escolar) na sociologia de Pierre Bourdieu. Diálogo Educ., Curitiba, v. 13, n. 38, p. 411-437, jan./abr. 2013.

Submetido em: 18/11/2016

Aprovado em: 14/12/2016

\title{
BLACK UNIVERSITY STUDENTS AND THE SCHOLAR-CULTURAL HERITAGE
}

\begin{abstract}
This article broaches three life experiences of quota black students at the Federal University of Santa Catarina, which were reported through interviews. The theoretical framework brings on the concepts developed by the sociologist Pierre Bourdieu, especially regarding to the different types of capital raised by the author - as the economic, cultural, social, symbolic, linguistic and scholar capital, to analyze the trajectories of scholar and collegial life. From the life trajectories of the students, are especially highlighted their cultural and scholar family heritage and how they mobilized this inheritance in their favor. In the university field, however, the racism, the gender discrimination and the "differences" intersect for the social reproduction, in the terms of Kimberlé Crenshaw and Pierre Bourdieu. The Affirmative Actions have been trying to break with the logic of social reproduction, creating the conditions for new relations in the university field, enriching the social practices in these environments by the inclusion of social, cultural and ethnic differences.
\end{abstract}

Keywords: Black Women. Capitals. Cultural and Scholar Heritage. 